\title{
Potential of Rhizobacteria for Bioremediation of Lead Accumulation in Rice Plants
}

\author{
Jintanart Wongchawalit ${ }^{1}$, Taniga Noitanom ${ }^{2}$, Thanawan Panich-pat ${ }^{2 *}$ \\ ${ }^{1}$ Department of Microbiology, Faculty of Liberal Arts and Science, Kasetsart University, Kamphaengsaen Campus, \\ Nakhon Pathom, Thailand \\ ${ }^{2}$ Research Cluster of Environmental Science and Technology, Department of Science, Faculty of Liberal Arts \\ and Science, Kasetsart University, Kamphaengsaen Campus, Nakhon Pathom, Thailand
}

Received: 13 November 2019

Accepted: 28 December 2019

\begin{abstract}
This research was conducted in a greenhouse pot experiment to investigate the efficiency of leadresistant bacterial inoculation on lead accumulation in rice by comparing a variety of isolated bacteria strains (TK1, TK3, RV2, RV4) and evaluating their growth. Additionally, lead accumulation in different parts of rice plants and the ability in BCF and TF were observed. The results showed in terms of growth performance (height, fresh weight and dry weight) that there was no significant difference between rice plants grown in uncontaminated and lead-contaminated soils. The highest lead accumulation was found in roots of TK3 (57.67 mg kg-1) Enterobacter sp. inoculum, followed by shoots of TK3 (19.50 mg kg-1), and grains of RV2 (0.55 $\left.\mathrm{mg} \mathrm{kg}^{-1}\right)$ Pseudomonas chlororaphis subsp. inoculum. Thus, lead concentration in grains on day 95 of the experiment exceeded the European Union Standard $\left(0.2 \mathrm{mg} \mathrm{kg}^{-1}\right)$, which might not be safe for human consumption but did not exceed the standard as animal feed $\left(30 \mathrm{mg} \mathrm{kg}^{-1}\right)$. The experimental rice plants in this study were not suitable for using in cleaning up lead-contaminated soil because the values of BCF and TF values were less than 1, but Bacillus subtilis strain EB31 from TK1 had the highest potential for lead bioremediation.
\end{abstract}

Keywords: lead, lead-resistant bacteria, accumulation, rice, bioremediation

\section{Introduction}

At present, environmental problems and pollution have increased significantly. It is a problem in the areas of soil, water resources and air, which have a negative impact on the environment. The problem of heavy metal contamination in soil is another serious problem. All over the world you can find crises related

*e-mail: faastwp@ku.ac.th to these pollutants due to the use of chemicals in large quantities generating hazardous waste [1]. Lead is an important raw material for the battery industry, lead casting industry and oil refineries. Additionally, lead is used in the soldering of various metals, and it has many benefits and is also a huge penalty for humans. Lead accumulated in soil, water and air has an impact on health of living things around the contaminated area. Lead is toxic to the nervous and circulatory systems. Lead-contaminated soil is an important environmental problem because of its toxic effect, its accumulation throughout the food chain, and the risk 
of groundwater contamination [2]. Moreover, lead accumulation in rice grains can also cause human and livestock environmental quality issues and adverse health complications [3]. Some studies in humans have shown that lead exposure may increase blood pressure, but the evidence is still inconclusive. Lead exposure may also cause anemia, resulting in a low number of red blood cells. The effects of high blood lead levels in children have been reported to reduce intelligence, cognitive development and function. Within the next 10 years, the generation of children with the highest historical lead exposures (those born in the 1960s, 1970s, and 1980s) will begin to enter the age at which dementia symptoms tend to emerge. Many will also enter the age at which lead stored in the skeleton may be remobilized at greater rates - particularly for women entering menopause and men and women experiencing osteoporosis [4]. In addition to humans, high lead concentration also shows plant toxicity such as lead causing a number of toxic symptoms in plants that may include retardation in growth (stunted growth), negative effects on photosynthesis (chlorosis), blackening of roots and other symptoms. Lead has the ability to inhibit photosynthesis, disturb mineral nutrition and water balance, change hormonal status and affect membrane structure and permeability [5].

Presently, has Thailand found more lead accumulated area in the environment. In 1998, Lead Concentrates (Thailand) Co., Ltd. operated lead mines at Clifford Creek Kanchanaburi. Due to less waste management, the company created a landfill system with poor management for waste discharge. Therefore, the occurrence lead to a large amount of lead contamination in the soil spread through the Klity village area. Thailand is now a top food-producing and exporting country. Agriculture has been cultivated by various economic crops such as rice and corn. Rice is an especially important economic crop for Thai society. Villagers have kept household consumption. It is a plant that is at risk of contamination of lead. There are several studies reported that rice grown in lead-contaminated areas can absorb lead and accumulate in different parts of rice.

Generally, soil microorganisms have the ability to improve the physical and chemical properties of soil for cropping. Additionally, soil microorganisms have developed their own mechanisms to resist inappropriate conditions of the soil - especially their metals toxicity resistant in soil contaminated with heavy metals. These microbes have a toxic mechanism and eliminate the toxic heavy metals from the aforementioned causes. Therefore in this study, we focus on the effectiveness of isolated rhizobacteria from lead-contaminated soil on the growth of rice grown in contaminated soil. Additionally, we compare lead accumulation in different parts of rice after being cultivated with different types of lead resistance bacteria in soil around rice root.

\section{Materials and Methods}

\section{Selection and Screening of Lead-Resistant Bacteria}

Lead-resistant bacteria were isolated by sampling rhizosphere soil from plant roots at Klity village, Kanchanaburi Province, Thailand. Soil sampling was performed at three collection points, including the area of sediment, a creek and rice fields. The dilution plate count technique was performed for screening and isolating lead-resistant bacteria on lead acetate agar containing $100 \mathrm{mg} \mathrm{l}^{-1}$ of lead. After incubation at $37^{\circ} \mathrm{C}$ for $48 \mathrm{~h}$, lead resistance bacteria formed the colonies on the medium. A single colony was selected and collected for testing their metal resistance ability of lead toxicity by inoculation isolated strains on a lead acetate agar plate containing various concentrations of lead from 100 to $500 \mathrm{mg} \mathrm{l}^{-1}$.

All selected bacteria were identified based on $16 \mathrm{~S}$ rRNA gene sequencing. DNA extraction was done by using an Isoplant II kit (Wako Pure Chemical Industrial Ltd., Japan). 16S rRNA gene was amplified by using polymerase chain reaction with Taq polymerase (Toyobo, Tokyo, Japan) and 16S rRNA universal primer (27F; 5'-AGAGTTTGATCCTGGCTCAG-3', forward primer) and 1525R (5'-AAAGGAGGTGATCCAGCC-3', reverse primer). The $1500 \mathrm{bp}$ of PCR products were sequenced by using an ABI PRISM 310 Genetic Analyzer. The nucleotide sequences of 16S rRNA of the unidentified bacteria were compared to those of 16S rRNA in the Genebank database using the BLAST method, and their sequence similarities at the National Center for Biotechnology Information (NCBI).

\section{Bacteria Inoculation}

Isolated bacteria strains were cultivated in lead acetate broth at $30^{\circ} \mathrm{C}$ for $48 \mathrm{~h}$. Cells were collected in the exponential phase of growth by centrifugation at $8,000 \mathrm{rpm}$ for $10 \mathrm{~min}$. Cell pellets were resuspended by sterile water to obtain cell density at McFarland No. $0.5\left(10^{8} \mathrm{CFU} \cdot \mathrm{ml}^{-1}\right)$. Suspended cells were inoculated to the soil surface $\left(50 \mathrm{ml} \cdot\right.$ pot $\left.^{-1}\right)$ three times a week after seedling emergence. Non-inoculation pots were made as control. All pot experiments were conducted under greenhouse conditions with constant sterile water and temperature $\left(20-30^{\circ} \mathrm{C}\right)$.

\section{Simple Soils and Plantings}

The soil culture for the experiment was collected from the Research and Development Institute Kamphaeng Saen. In preparation for the pot experiment, soil was air-dried for 2 weeks, then autoclaved, mixed and $2 \mathrm{~kg}$ added to every pot. Experiments were assigned to inoculate lead resistance bacterial strains to the treatments which were set-up as follows:

- Treatment: Control (sterile soil + rice) 
- Treatment: TK1 (lead contaminated soil + rice + bacterial strain Bacillus subtilis strain TK1).

- Treatment: TK3 (lead contaminated soil + rice + bacterial strain Enterobacter sp. strain TK3).

- Treatment: RV2 (lead contaminated soil + rice + bacterial strain Pseudomonas chlororaphis ssp. RV2).

- Treatment: RV4 (lead contaminated soil + rice + bacterial strain Microvirgula sp.RV4).

For treatment, TK1, TK3, RV2 and RV4 were added lead (II) acetate $500 \mathrm{mg} \mathrm{kg}^{-1}$ into pots. Rice was planted in a greenhouse at Kasetsart University, Kamphaeng Saen Campus. Rice seeds were sown in each pot. After the first pair of true leaves appeared, seedlings were thinned out and 1 uniform one per pot was allowed to grow. All treatments were done in triplicate by planting 3 pots for each treatment. The experimental design was completely randomized (CRD).

\section{Soil and Plant Sampling Analysis}

The soil samples were air-dried, homogenized, sieved through a $2 \mathrm{~mm}$ mesh and analyzed for total soil lead by flame atomic absorption spectrophotometry (Spectra AA 200), including soil $\mathrm{pH}$, electrical conductivity, organic matter and cation exchange capacity in Table 1. All treatments were carefully harvested on day 95 and washed with running tap water. Rice plant samples were divided into roots, shoots and grains. Roots and shoots were cut into small pieces, while grains were ground after all samples were dried at $80^{\circ} \mathrm{C}$ for 2 days. Approximately $0.2 \mathrm{~g}$ of a sample was dissolved in a $5 \mathrm{ml}$ mixture of $\mathrm{HNO}_{3}$ and $\mathrm{HClO}_{4}$ at the ratio of 2:1. Samples were digested in a block digester at $200^{\circ} \mathrm{C}$, filtered and adjusted to a volume of $50 \mathrm{ml}$ with distilled water. The lead content of the acid extract was determined using flame atomic absorption spectrophotometry (FAAS).

\section{Analysis of Plant Growth}

Growth of the rice plants was investigated by measuring the height, fresh weight and dry weight on day 95. The height measuring was done from the first part of the stem to the flag leaf. Weight was recorded as grams of fresh weight and dry weight.

\section{Phytoextraction Potential}

The amount of lead that is taken up by the rice plants can be measured as the bioconcentraction (BCF) and translocation factor (TF) [1]:

$$
\begin{gathered}
B C F=\frac{P b \text { Plant }(\mathrm{mg} / \mathrm{kg})}{P b \text { Soil }(\mathrm{mg} / \mathrm{kg})} \\
T F=\frac{P b \text { Plant in shoot }(\mathrm{mg} / \mathrm{kg})}{P b \text { Plant in root }(\mathrm{mg} / \mathrm{kg})}
\end{gathered}
$$

$\mathrm{BCF}$ and $\mathrm{TF}$ values higher than 1 are considered the appropriate choice for removal of these metals from polluted soils in the studied area. On the contrary, BCF and $\mathrm{BF}$ values less than 1 cannot be considered an appropriate choice for metal phytoextraction from the examined polluted soils.

\section{Data Analysis}

Data analysis was performed using analysis of variance (ANOVA), and all statistical analysis was done using SPSS software version 15 significantly based on 0.05 in most cases.

\section{Results}

\section{Lead Resistance Bacteria}

Four isolates (TK1, TK3, RV2 and RV4) of rhizophere bacteria from lead-contaminated soil were screened and tested their tolerance ability for lead toxicity. Isolates TK1, TK3, RV2 and RV4 were identified based on 16S rRNA gene sequence with high identity from $97-98 \%$ to be Bacillus subtilis strain EB31, Enterobacter sp., Pseudomonas chlororaphis sub sp., and Microvirgula sp., respectively (Table 2).

Table 1. Physico-chemical characteristics of the uncontaminated soil and contaminated soil at the beginning and the end of the experiment.

\begin{tabular}{|c|c|c|c|c|}
\hline \multirow{2}{*}{ Parameters } & \multicolumn{4}{|c|}{ Analysis value } \\
\cline { 2 - 5 } & Uncontaminated soil & \multicolumn{2}{|c|}{ Contaminated soils } \\
\cline { 2 - 5 } & Day 0 & Day 95 & Day 0 & Day 95 \\
\hline $\mathrm{pH}$ & 6.69 & 6.62 & 7.26 & 6.92 \\
\hline $\mathrm{EC}\left(\mathrm{dS} \mathrm{m}^{-1}\right)$ & 7.20 & 6.35 & 3.95 & 8.58 \\
\hline Organic matter $(\%)$ & 4.30 & 5.24 & 5.64 & 17.49 \\
\hline CEC $\left(\mathrm{cmol} \mathrm{kg}^{-1}\right)$ & 7.75 & 8.21 & 13.96 & 233.67 \\
\hline Total soil $\mathrm{Pb}\left(\mathrm{mg} \mathrm{kg}^{-1}\right)$ & 5.48 & 2.39 & 500 & 11.75 \\
\hline Available soil Pb $\left(\mathrm{mg} \mathrm{kg}^{-1}\right)$ & 0.93 & 1.22 & & 20.10 \\
\hline
\end{tabular}


Table 2. Bacterial isolates of each isolate and bacteria in NCBI database using BLAST program.

\begin{tabular}{|c|c|c|c|}
\hline Code number & GenBank acc.no & Best match with & Identity \% \\
\hline TK1 & KC197815.1 & Bacillus subtilis strain EB31 & $98 \%$ \\
\hline TK3 & KF582906.1 & Enterobacter sp. & $97 \%$ \\
\hline RV2 & AB680101.1 & Pseudomonas chlororaphis subsp. & $97 \%$ \\
\hline RV4 & KR029290.1 & Microvirgula sp. & $98 \%$ \\
\hline
\end{tabular}

\section{Plant Growth on Day 95}

The physico-chemical characteristics of uncontaminated and lead-contaminated soil at the end of the experiment (95 days) were presented in Table 1. The lead uptake is mainly regulated by $\mathrm{pH}$, particle size, and cation exchange capacity of the soil, root exudation and by different other physical and chemical parameters [5]. Most soil $\mathrm{pH}$ values decreased, indicating that increasing acidity may affect the solubility of lead in the soil increase, resulting in rice plants absorbing lead better. The soil organic matter and CEC were found to increase, meaning that the lead remaining in the soil was mostly absorbed in rice plants, but did not cause toxicity to the plants. The growth of rice plants in both uncontaminated soil and lead-contaminated soil

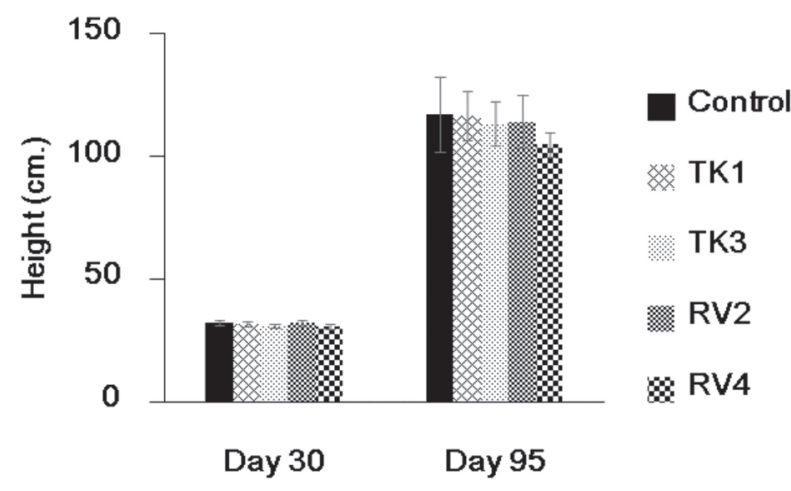

Fig. 1. Height of rice plants after 30 and 95 days in control and contaminated soil.

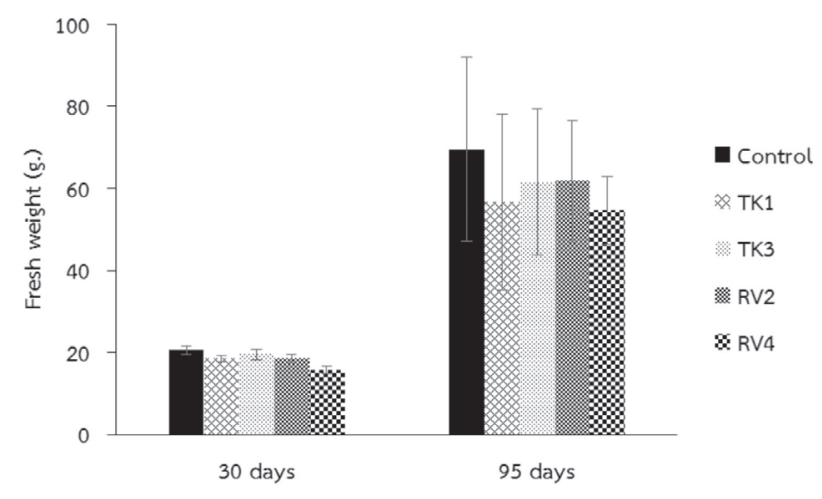

Fig. 2. Fresh weight of rice plants after 30 and 95 days in control and contaminated soils. was evaluated by height, fresh weight and dry weight. The results showed the average height of control rice $117.33 \pm 15.14 \mathrm{~cm}$, which was not a significant difference (Fig. 1). The average heights of rice plants in TK1, TK3, RV2 and RV4 were $116.67 \pm 9.87,113.67 \pm 9.07$, $114.33 \pm 10.69$ and $105 \pm 5.00 \mathrm{~cm}$, respectively.

The average fresh weight of rice plants in control was $69.46 \pm 22.46 \mathrm{~g}$, and the comparable rice plants in contaminated soils were not significantly different (Fig. 2). The average fresh weights of rice plants in TK1, TK3, RV2 and RV4 were 56.72 $\pm 21.46,61.57 \pm 17.89$, $61.77 \pm 14.86$ and $54.55 \pm 8.24 \mathrm{~g}$, respectively.

The average dry weight of rice plants in control were $66.93 \pm 22.46 \mathrm{~g}$, and the comparable rice plants in contaminated soils were not significantly different (Fig. 3). The average dry weights of rice plants in TK1, TK3, RV2 and RV4 were 55.26 $\pm 21.46,58.27 \pm 17.89$, $58.94 \pm 8.24$ and $50.80 \pm 8.24 \mathrm{~g}$, respectively.

The results of bacterial identification base on $16 \mathrm{~S}$ rRNA sequences classified bacteria into 2 groups: (1) Gram-positive bacteria include Bacillus subtilis strain TK1, and (2) Gram-negative bacteria include Enterobacter sp. strain TK3, Pseudomonas chlororaphis subsp. RV2 and Microvirgula sp. strain RV4. The result of inoculating bacteria in the pots was tested by considering the height, fresh weight, and dry weight of rice plants. We found that Bacillus subtilis strain TK1 rice grew the highest and that Microvirgula sp. strain RV4 rice was the shortest. The highest fresh weight and dry weight of rice plants in lead-contaminated soil showed that Pseudomonas chlororaphis subsp. RV2 was highest and Microvirgula sp. strain RV4 was lowest.

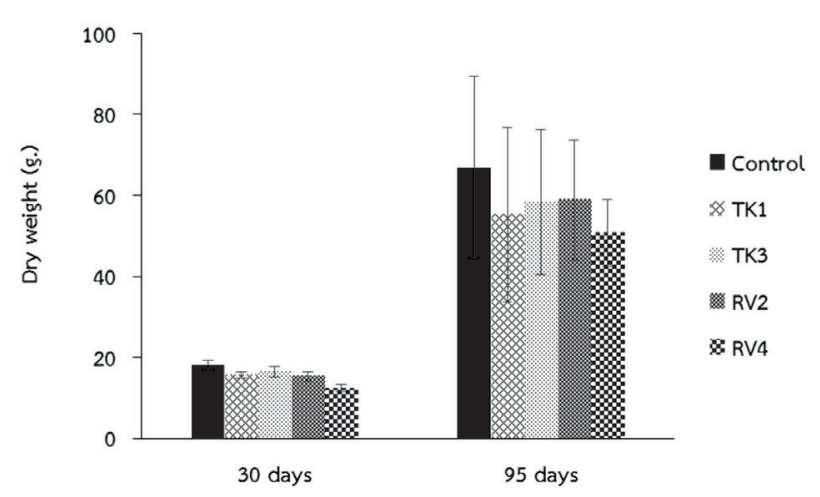

Fig. 3. Dry weight of rice plants after 30 and 95 days in control and contaminated soils. 
Table 3. Lead concentrations in rice plants on day 95 in lead-contaminated soils ( $\mathrm{mg} \mathrm{kg}^{-1}$ dry weight).

\begin{tabular}{|c|c|c|c|}
\hline \multirow{2}{*}{ Treatments } & \multicolumn{3}{|c|}{ Lead concentrations in plants } \\
\cline { 2 - 4 } & Roots & Shoots & Grains \\
\hline Treatment control & $1.47 \pm 0.05$ & $0.53 \pm 0.12$ & $0.06 \pm 0.04$ \\
\hline Treatment TK1 & $42.82 \pm 16.94^{\mathrm{b}}$ & $17.03 \pm 0.47$ & $0.47 \pm 0.11^{\mathrm{a}}$ \\
\hline Treatment TK3 & $57.67 \pm 1.60^{\mathrm{a}}$ & $19.50 \pm 0.59$ & $0.52 \pm 0.18^{\mathrm{a}}$ \\
\hline Treatment RV2 & $51.69 \pm 1.12^{\mathrm{a}}$ & $17.01 \pm 1.81$ & $0.55 \pm 0.14^{\mathrm{a}}$ \\
\hline Treatment RV4 & $50.48 \pm 1.41^{\mathrm{a}}$ & $16.12 \pm 0.66$ & $0.26 \pm 0.05^{\mathrm{b}}$ \\
\hline ANOVA (F-test) & $*$ & NS & $*$ \\
\hline
\end{tabular}

Values followed by the same letter do not differ statistically according to the variance (ANOVA) test at $p \leq 0.05$. NS: non-significant. $* p \leq 0.05$

\section{Lead Concentrations in Plants}

Lead accumulation in different parts of the rice plant was measured as lead concentrations in unit of $\mathrm{mg} \mathrm{kg}^{-1}$ dry weight. The concentrations of lead in roots of rice plants were significantly higher $(p \leq 0.05)$ compared to other parts. In particularl, in treatment TK3 as rice grown in lead-contaminated soil inoculated with Enterobacter sp. strain TK3 showed, the highest lead concentration in roots was $57.67 \pm 1.60 \mathrm{mg} \mathrm{kg}^{-1}$ and the lowest was $42.82 \pm 16.94 \mathrm{mg} \mathrm{kg}^{-1}$ inoculated with Bacillus subtilis strain TK1 (Treatment TK1). Lead concentrations in shoots of rice plants were not significantly different $(p \leq 0.05)$. In treatment TK3, as rice grown in lead-contaminated soil inoculated with Enterobacter sp. strain TK3 was the highest lead concentration in shoots $19.50 \pm 0.59 \mathrm{mg} \mathrm{kg}^{-1}$ and the lowest lead concentration in shoots inoculated with Microvirgula sp. strain RV4 was $16.12 \pm 0.66 \mathrm{mg} \mathrm{kg}^{-1}$. Lead concentration in grains was significantly different $(p \leq 0.05)$. In Treatment RV2 as rice grown in lead contaminated soil inoculated with Pseudomonas chlororaphis subsp. strain RV2 was the highest lead concentration in grains $0.55 \pm 0.14 \mathrm{mg} \mathrm{kg}^{-1}$ and the lowest - in grains inoculated with Microvirgula sp. strain RV4 - was $0.26 \pm 0.05 \mathrm{mg} \mathrm{kg}^{-1}$ (Table 3).

\section{Phytoextraction Potential}

The BCF and TF values of metals are shown in Table 4. The BCF values of treatments were lower than 1 for all treatments. In particular, the ranges of values for treatments TK1, TK3, RV2 and RV4 were $0.10-0.15$. In the same way, the TF values of all treatments were lower than 1 . In particular, the ranges of values for treatments TK1, TK3, RV2 and RV4 were 0.33-0.70 (Table 4).

\section{Discussion}

The success of bioremediation depends upon the high biomass of plant species, the bioavailability of metals for plant uptake and soil microorganisms around the rhizosphere. The phytoavailability of metals is influenced by soil-associated factors such as $\mathrm{pH}$, redox potential, cation exchange capacity, soil type, and soil texture, and by plant-associated factors such as root exudates and root rhizosphere processes (microorganism). The factors influencing the bioavailability of metals in soil are $\mathrm{pH}, \mathrm{CEC}$, clay content and organic matter content. The growth of the rice in uncontaminated soils and lead-contaminated

Table 4. Bioconcentration factor (BCF) and translocation factor (TF) in the treatments.

\begin{tabular}{|c|c|c|}
\hline Treatments & Bioconcentration factor & Translocation factor \\
\hline Treatment control & $0.01 \pm 0.00$ & $0.50 \pm 0.04$ \\
\hline Treatment TK1 & $0.10 \pm 0.03$ & $0.70 \pm 0.50^{\mathrm{a}}$ \\
\hline Treatment TK3 & $0.15 \pm 0.01$ & $0.54 \pm 0.34^{\mathrm{a}}$ \\
\hline Treatment RV2 & $0.14 \pm 0.01$ & $0.34 \pm 0.04^{\mathrm{b}}$ \\
\hline Treatment RV4 & $0.13 \pm 0.01$ & $0.33 \pm 0.01^{\mathrm{b}}$ \\
\hline ANOVA (F-test) & NS & $*$ \\
\hline
\end{tabular}

Values followed by the same letter do not differ statistically according to the Variance (ANOVA) test at $\mathrm{P} \leq 0.05$. NS: non-significant. (mean \pm standard error, three replicates).

$* \mathrm{P} \leq 0.05$. 
soils that showed average height of rice was not significantly different $(p \leq 0.05)$. Average growth of roots and shoots of rice in uncontaminated soils was higher than rice grown in lead-contaminated soils. These results may refer to the different growth of these plants to lead toxicity or inhibit growth as a result of the average growth of roots and shoots to decrease. According to Umair et al. [6] found within root cells of rice, lead is unevenly distributed where root cells hinder the apoplastic and symplastic transport of lead to restricts its translocation toward shoots. Each treatment of experiments in lead-contaminated soils that showed average height of rice plants was not significantly different than that found in rice grown in lead-contaminated soil inoculated with Bacillus subtilis strain TK1 being the highest, which Bacillus subtilis can produce biopolymer that has amino group binding characteristic metal ions to adjust soil structure to be fertile soil. For rice grown in lead-contaminated soil inoculated with Microvirgula sp., RV4 showed the lowest value of height due to formic acid produced to make the soil more acidic, resulting in heavy metals that can better dissolve water. The accumulation of lead in plants is much higher and toxicity may slowly grow plants or cause plants to die [7].

Fresh weight and dry weight of rice plants in uncontaminated soils and lead-contaminated soils showed that the average weight of rice was not significantly different because measuring organic matter and cation exchange capacity on day 95 in uncontaminated soils and lead-contaminated soils, both values increased and showed a high organic matter content, the more firmly bound organic matter in soil enhanced the retention of lead the resulting lead accumulation and toxicity in plants was lower. The highest of fresh weight and dry weight of rice grown in lead-contaminated soil inoculated with Pseudomonas chlororaphis subsp. RV2 and the lowest of rice grown in lead-contaminated soil inoculated with Microvirgula sp. RV4 owing to Pseudomonas chlororaphis subsp. RV2 has a mechanism to reduce lead in contaminated sources by absorbing lead with functional groups on the cell surface as a result in less accumulation of lead in plants. Rice plants inoculated with Pseudomonas chlororaphis subsp. RV2 grew well. On the other hand, rice plants inoculated with Microvirgula sp. RV4 make the soil acidic and more soluble for metals. Rice plants had higher lead accumulation, resulting in toxicity causing slower growth [7].

The most feasible biological treatment is to combine microbes with treatment plants. Therefore, bioremediation is an eco-friendly and efficient method of reclaiming environments contaminated with heavy metals by making use of the inherent biological mechanisms of microorganisms and plants to eradicate hazardous contaminants [8]. Heavy metals are nonbiodegradable and could be toxic to microbes. Several microorganisms have evolved to develop detoxification mechanisms to counter the toxic effects of these inorganic metals [9]. From this study, in each treatment of lead accumulation in various parts of rice plants in lead-contaminated soil showed that rice plants inoculated with Bacillus subtilis strain TK1 had an average amount of lead accumulation in roots less than other treatments, but the rice plants of this treatment as the highest. According to Lugauskas et al. [10], Bacillus subtilis released polysaccharide with functional groups $(\mathrm{OH}-)$, holding lead $\left(\mathrm{Pb}^{2+}\right)$ by fixing the metal on the cell surface. Moreover, Bacillus subtilis can produce biopolymer to restructure soil to be fertile soil that is one reason make plants grow. For Pseudomonas chlororaphis subsp. RV2 no spore that meant the environment of its better than Bacillus subtilis thus, one of the reasons that Bacillus subtilis had better remediation of lead-contaminated soils. In accordance with Chen et al. [11], who studied the remediation of lead-resistant bacteria to lead-polluted soil in pot experiments by using two lead-resistant bacteria (Bacillus pumilus and Pseudomonas aeruginosa) from the soil of a lead-mining district (Heilongjiang Province, China) and inoculated into soil planted with cabbages and different levels of lead (0, 200, 400, 600, 800 and $1,000 \mathrm{~Pb} \mathrm{mg} \mathrm{kg}{ }^{-1}$ dry soil), inoculated samples after 48 days showed that Bacillus pumilus exhibited more power of remediation when lead concentration was less than $800 \mathrm{mg} \mathrm{kg}$, while Pseudomonas aeruginosa performed well when lead concentration was less than $1,000 \mathrm{mg} \mathrm{kg}^{-1}$, and thus the decrease of lead concentration in rhizospheric soil is an important indicator of remediation by the two lead-resistant bacteria. Salas et al. [12] found that Pseudomonas aeruginosa could tolerate heavy metals using resistant genes and genes that carry on plasmid, which play an important role in increasing the efficacy of the strain in bioaccumulation and tolerance. However, the capability of lead remediation of rice inoculated with Microvirgula sp. RV4 and Enterobacter sp. TK3 lower than Bacillus subtilis and Pseudomonas chlororaphis subsp. due to Enterobacter sp. is a bacterium that does not produce spores and can digest lactose to form acids and gases. Rice inoculated with Microvirgula sp. can react with formic acid according to Gadd [13], who showed that oxalic acid, citric acid and formic acid can change the heavy metal and be transformed into a plant that absorbed through the roots. This will allow soil to become more acidic, resulting in plants better absorbing heavy metals.

The bioconcentration factor (BCF), which is defined as the ratio of metal concentration in the roots to that in soil and translocation factors (TF), is defined as the ratio of metal concentration in shoots to roots - both of which can be used to estimate a plant's potential for phytoremediation [1]. The highest of bioconcentration factors were rice inoculated with Enterobacter sp. TK3 because it can digest lactose to form acids and gases, resulting in more soluble heavy metals, which helps plants to absorb heavy metals better, thus causing plants to accumulate high heavy metals. 
All treatments had BCF values less than one, thus were unsuitable for phytoextraction. For TF this means a plant's ability to translocate metals from the roots to the shoots, with TF values of all treatments less than one due to rhizobacteria playing an important role in the movement and fixation of heavy metals and also influence to absorb lead in plants as well. Liu et al. [14] found that the varietal differences regarding lead translocation might be associated with the differences in lead forms within the rice plant, leadloading capacity, and possible transformations in the xylem tissues. So, a great variation exists among lead concentration within plant parts. Normally, lead concentration is recorded from maximum to minimum in the following order: $\operatorname{root}>$ shoot $>$ ear (up to heading stage)>grain (at ripening stage) [6]. According to Sukyankij et al. [15], who studied phytoaccumulation of sorghum for growth on lead-contaminated soil, the highest lead concentration is in roots $>$ stems and leaves $>$ pericarps $>$ seeds. The degree of variation among these parts significantly depends on soil lead concentration and plant growth stages. Furthermore, grain lead concentration significantly correlates with shoot and ear lead contents at the heading stage [14]. However, lead concentration in grains on day 95 of the experiment exceeded the European Union Standard (0.2 $\mathrm{mg} \mathrm{kg}^{-1}$ ), which might not be safe for human consumption but did not exceed the standard as animal feed (30 mg kg-1).

\section{Conclusions}

We determined the potential of rhizobacteria for bioremediation of lead accumulation in rice plants by comparing various strains of bacteria (TK1, TK3, RV2, RV4) and evaluating lead accumulation in different parts of a rice plant. The results showed that bacteria 2 groups isolated around the roots of rice plants that were resistant to lead concentration: (1) Gram-positive bacteria include Bacillus subtilis strain TK1. (2) Gram-negative bacteria include Enterobacter sp. TK3, Pseudomonas chlororaphis subsp. RV2 and Microvirgula sp. RV4 and was found rice plants inoculated with Bacillus subtilis strain TK1 to reduce the highest lead concentration in most parts of rice plants and continue to grow best. Lead concentrations in different parts of rice plants showed the highest lead concentrations in roots. The bioconcentration factor $(\mathrm{BCF})$ and translocation factor $(\mathrm{TF})$ values of all treatments were less than 1; therefore, rice plants in this experiment were not effective for cleaning up leadcontaminated soil.

\section{Acknowledgements}

This work was funded by the Capacity Building Program for New Research 2018 from the National
Research Council of Thailand (NRCT) and Environmental Science and Technology Program.

\section{Conflict of Interest}

The authors declare no conflict of interest.

\section{References}

1. YOON J., CAO X., ZHOU Q., MA., L.Q. Accumulation of $\mathrm{Pb}, \mathrm{Cu}$ and $\mathrm{Zn}$ in native plants growing on a contaminated Florida site. Science of the Total Environment. 368, 456, 2006.

2. JEBARA S.H., ABDELKERIM S., FATNASSI I.C., CHIBOUB M., SAADANI O., JEBARA M. Identification of effective $\mathrm{Pb}$ resistant bacteria isolated from Lens culinaris growing in lead contaminated soils, Journal of Basic Microbiology 55, 3, 346, 2015.

3. SHRAIM A.M. Rice is a potential dietary source of not only arsenic but also other toxic elements like lead and chromium, Arabian Journal of Chemistry 10, 3434, 2014.

4. AARON R. Childhood lead exposure and adult neurodegenerative disease, Journal of Alzheimer's disease, 64 (1), 17, 2018.

5. FAROUK S. N., MUHAMMAD A. The effect of lead on plants in terms of growing and biochemical parameters: a review, MOJ Ecology \& Environmental Sciences, 3 (4), 265, 2018.

6. UMAIR A., ADAM S. K., ZHAOWEN M., SADDAM H., SHAKEEL A. A., IMRAN K., RANA N. A., XIANGRU T. Lead toxicity in rice: effects, mechanisms, and mitigation strategies - a mini review, Environmental Science and Pollution Research, Springer-Verlag Berlin Heidelberg, 2015.

7. SUBHASH Y., MIN J.P., SANG S.L. Microvirgula curvata sp. nov., isolated from hydrocarbon-contaminated soil, and emended description of the genus Microvirgula. International Journal of Systematic and Evolutionary Microbiology 66, 5309, 2016.

8. OJUEDERIE O.B., BABALOLA O.O. Microbial and plant-assisted bioremediation of heavy metal polluted environments: a review. International Journal of Environmental Research and Public Healt 14 (12), 1504, 2017.

9. BERNAED E.I., STANLEY I.R.O., GRACE O.I., EBERE P.A., ABRAHAM O.A., IBE K.E. Toxicity and bioremediation of heavy metals contaminated ecosystem from tannery wastewater: a review. Journal of Toxicology, Published online 2018.

10. LUGAUSKAS A., LEVINSKAITE L., PEEIULYTE D., REPEEKIENE J., MOTUZAS A., VAISVALAVIEIUS R, PROSYEEVAS I. Effect of copper, zinc and lead acetates on microorganisms in soil. Ekologija 1, 61, 2005.

11. CHEN B., LIU J.N., WANG Z., DONG L., FAN J.H., QU J.J. Remediation of Pb-resistant bacteria to $\mathrm{Pb}$ polluted soil. Journal of Environmental Protectection 2, 130, 2011.

12. SALAH A., MAMDOUH S. E. AYMAN F. Trends in heavy metals tolerance and uptake by Pseudomonas aeruginosa. IntechOpen Published: September $27^{\text {th }} 2019$.

13. GADD G.M. Heavy metal accumulation by bacteria and other microorganisms.

14. Experientia 46(8), 834, 1990. 
15. LIU J., MA X., WANG M., SUN X. Genotypic differences among rice cultivars in lead accumulation and translocation and the relation with grain $\mathrm{Pb}$ levels. Ecotoxicology and Environmental Safety 90, 35, 2013.
16. SUKYANKIJ S., THEANKINGKAEW S., PANICHPAT T. Phytoaccumulation of sorghum for growth on lead contaminated soil. Advances in Environmental Biology 10 (10), 47, 2016 